\title{
DRENAGEM DE EFUSÃO PLEURAL POR DRENO INTRODUZIDO POR TORACOSCOPIA EM CAVALO COM PLEUROPNEUMONIA
}

\author{
(Pleural effusion drainage by thoracoscopy drain introduction in horse's \\ pleuropneumonia)
}

\author{
Bruna Lampe Zielinski ${ }^{*}$, Vanessa Alberini ${ }^{2}$, Jéssica Rodrigues Silva-Meirelles ${ }^{1}$, Luíza Costa Barcellos ${ }^{1}$, \\ Tilde Rodrigues Froes ${ }^{1}$, Peterson Triches Dornbusch ${ }^{1}$

\footnotetext{
${ }^{1}$ Universidade Federal do Paraná, Curitiba, Paraná, Brasil. *Correspondência: bruna@zielinski.com.br

2 Pontifícia Universidade Católica do Paraná, Curitiba, Paraná, Brasil
}

\begin{abstract}
RESUMO: Tendo em vista que afecções do sistema respiratório são grandes responsáveis por perdas de rendimento atlético de equinos, faz-se necessário o diagnóstico e tratamento precoce da doença para que o animal possa retornar à sua rotina sem perder de forma drástica sua performance. O presente artigo tem como objetivo abordar a técnica de toracoscopia como método diagnóstico e auxiliar no tratamento da pleuropneumonia em equinos, bem como relatar o caso de um cavalo com histórico de febre intermitente não responsiva à tratamentos com antibióticos e antipiréticos, sinais clínicos compatíveis com pleuropneumonia e diagnóstico confirmado pela ultrassonografia torácica. O exame toracoscópico bilateral foi essencial para observação e lavagem da cavidade torácica por meio de um dreno de silicone, e é sabido que a colocação de drenos torácicos com auxílio da toracoscopia resulta em alto índice de recuperação atlética dos animais. Desta forma, a toracoscopia vem como uma grande auxiliadora para a clínica de equinos, pois permite que o médico veterinário, além de ter uma visão mais completa da cavidade torácica e detalhes específicos do caso, também possa usar este método de exame complementar no auxílio ao tratamento pela drenagem da efusão pleural e fixação de dreno, garantindo melhora clínica do animal e rápida recuperação.
\end{abstract}

Palavras-chave: endoscopia; equinos; sistema respiratório; tórax

ABSTRACT: This article reports the disorders of the respiratory system are responsible for losses of horse's athletic performance. Early diagnosis and treatment can return to its routine without losing performance. The objective is to approach the thoracoscopic technique as diagnostic as auxiliary method for the treatment of pleuropneumonia in horses. This case is about a horse with a history of intermittent fever not responsive to antibiotics and antipyretics treatments, clinical signs consistent with pleuropneumonia and diagnosed by thoracic ultrasonography. Bilateral thoracoscopic examination was essential for observation and lavage of the thoracic cavity through a silicone drain, and it is known that the placement of thoracic drains with the aid of thoracoscopy results in a high rate of athletic recovery. Thoracoscopy comes as a great support to equine clinic as it allows the veterinarian to have a complete evaluation of the thoracic cavity and specific details of the case. This complementary exam and treatment for pleural effusion drainage and drain fixation ensures clinical improvement for the animal and short recuperation time.

Keywords: endoscopy; equine; respiratory system; thorax 


\section{INTRODUÇÃO}

A pleuropneumonia equina, também conhecida como "febre do embarque" ou "do transporte", está relacionada a queda de imunidade devido ao estresse agudo e agentes microbianos (PO et al., 2013). É caracterizada por uma inflamação do parênquima pulmonar associada a colonização bacteriana, desenvolvimento de abscessos pulmonares e/ou pneumonia, com posterior extensão à pleura visceral e ao espaço pleural (LIGHT et al., 1980).

O agente etiológico mais comum é - Streptococcus sp, bactéria grampositiva. Outros gêneros bacterianos também podem ser isolados, como Pasteurella spp., Pseudomonas spp., Staphylococcus spp., Actinobacillus spp., e enterobactérias (E. coli, Klebsiella spp., Enterobacter spp.) (RAIDAL, 1995). É uma afecção do sistema respiratório frequente na rotina clínica de cavalos, principalmente nos animais atletas, submetidos à estabulagem ou a longos períodos de transporte e/ou treinamentos constantes, sem predileção por idade ou raça. Os animais jovens ou de competição, que são transportados por longas distâncias, apresentam maior risco de contrair a doença (SWEENEY \& REILLY, 2001).

Os cavalos com pleuropneumonia apresentam sinais clínicos como intolerância ao exercício, letargia, febre e tosse, podendo ocorrer secreção nasal e pleurodinia durante a auscultação respiratória. Quando houver presença de efusão pleural, pode-se observar hiper-ressonância ventral à percussão torácica (WILKINS, 2003). Ainda podem ser encontrados aumento da frequência respiratória, edema subesternal e abdução dos cotovelos devido a dor (SWEENEY \& REILLY, 2001).
Dentre os diagnósticos diferenciais para pleuropneumonia pode-se citar derrame neoplásico, insuficiência cardíaca congestiva, hemorragia torácica, entre outras (MAIR, 2012).

A toracoscopia é um exame que pode ser utilizado em diversas situações na medicina equina, dentre elas na avaliação de casos de doenças pulmonares. A inspeção visual da cavidade pleural auxilia no diagnóstico de doenças torácicas ou identificação de corpos estranhos em conjunto com outras técnicas, como radiografia, ultrassonografia, aspiração traqueal e lavado broncoalveolar. Além de prestarse como método diagnóstico, a toracoscopia também é recomendada na colocação de drenos torácicos contribuindo com o melhor posicionamento desses na localização de massas e abscessos, aumentando a segurança do procedimento (VACHON \& FISCHER, 1998).

Esta técnica de endoscopia pode ser realizada com endoscópio flexível ou rígido (DE ZOPPA et al., 2001), podendo 0 animal estar em posição quadrupedal sob anestesia local associada ou não a sedativos e analgésicos. A posição quadrupedal permite melhor visualização das estruturas quando comparada ao decúbito lateral com 0 animal sob anestesia geral (FREEMAN, 1991; MACKEY \& WHEAT, 1985; MANSMANN \& BERNARD-STROTHER, 1985).

De acordo com a anatomia normal do cavalo, pelo exame toracoscópico é possível observar o pulmão colapsado tanto no hemitórax direito quanto no esquerdo, porém pelo acesso no hemitórax direito também podem ser identificados artéria aorta, esôfago e veia ázigos. Com a abordagem torácica mais caudal, é possível observar o pulmão aderido ao mediastino pelo 
ligamento pulmonar, e acima deste a membrana mediastinal dorsal, que permite a visualização do pulmão contralateral em movimento durante a respiração, indicando a ausência de pneumotórax bilateral (PERONI et al., 2001).

O objetivo desse trabalho é apresentar a aplicabilidade da toracoscopia em um cavalo diagnosticado com pleuropneumonia e demonstrar o uso dessa técnica no diagnóstico e tratamento desta afecção.

\section{MATERIAL E MÉTODOS}

Uma fêmea equina, Puro Sangue Inglês, de três anos de idade, pesando $408 \mathrm{~kg}$, foi atendida no Hospital Veterinário da Universidade Federal do Paraná (HV-UFPR) com histórico de febre intermitente há cinco dias e tratamento prévio por veterinário autônomo no Jockey Clube do Paraná (JCP) com penicilina, gentamicina, enrofloxacina, metronidazol, flunixina meglumina, dipirona, soro vitaminado e polivitamínicos. Além da administração de antibióticos e anti-inflamatórios, ultrassonografia torácica também havia sido realizada no JCP, na qual notou-se evidência de efusão pleural em ambos os hemitórax. No presente relato não houve um fator predisponente identificado, como transporte ou competição.

No HV-UFPR realizou-se exame físico no qual o animal apresentava mucosa oral levemente congesta, taquipnéia $(40 \mathrm{mpm})$, apatia, frequência cardíaca normal (36bpm), motilidade intestinal normal (com presença de uma descarga cecal em 3 minutos), tempo de preenchimento capilar (TPC) e turgor de pele normais (menor que dois segundos), indicando que 0 animal estava hidratado. Coletou-se sangue para hemograma e bioquímica sérica, urina para urinálise e foi realizado novo exame ultrassonográfico entre o $4^{\circ}$ e $10^{\circ}$ espaços intercostais (EIC) em ambos os hemitórax com aparelho Ultrasonix Sonix System $\AA$, modelo Sonix 01, e probe convexa com frequência de 2 a 5 $\mathrm{MHz}$, confirmando efusão pleural bilateral. Desta forma optou-se pela realização de exame toracoscópico bilateral, para observação e lavagem da cavidade torácica por meio de um dreno de silicone.

Para tanto, o paciente foi mantido em posição quadrupedal em tronco de contenção sob sedação com Detomidina $1 \%(40 \mu \mathrm{g} / \mathrm{kg})$; realizou-se tricotomia do $4^{\circ}$ ao $16^{\circ}$ EIC bilateral e antissepsia cirúrgica com iodo degermante, iodo tópico e álcool iodado. O acesso para colocação do endoscópio foi realizado no $8^{\circ} \mathrm{EIC}$, imediatamente abaixo da inserção do músculo trapézio, de acordo com Vachon \& Fischer (1998). O procedimento foi realizado em ambos os lados conforme a técnica descrita por Mackey e Wheat (1985). O acesso para colocação dos drenos foi realizado no $6^{\circ}$ EIC, na altura da articulação escapuloumeral. Ambos os acessos foram precedidos por anestesia local infiltrativa com lidocaína $2 \%$, seguida de incisão de aproximadamente $2 \mathrm{~cm}$ na pele e tecido subcutâneo. Os músculos intercostais foram divulsionados e a pleura perfurada com pinça hemostática de Crile. Nos acessos do endoscópio e do dreno colocou-se endotip de $11 \mathrm{~cm}$, de ambos os lados. Pelo acesso do endotip colocado no $8^{\circ} \mathrm{EIC}$ foi inserido o videoendoscópio (marca Karl Storz®, modelo rígido, ângulo de visão de $30^{\circ}$, $10 \mathrm{~mm}$ de diâmetro, $54 \mathrm{~cm}$ de comprimento e fonte de luz xenon) e no endotip colocado no $6^{\circ}$ EIC inseriu-se uma sonda nasogástrica $\mathrm{n}^{\circ} 20$ (Figura 1A).

De ambos os hemitórax foram coletadas amostras de líquido pleural para exame bacteriológico e antibiograma, seguida de lavagem e drenagem com solução salina $(\mathrm{NaCl}$ $0,9 \%$, inicialmente com o aspirador de 
secreções e posteriormente com auxílio da sonda nasogástrica. Mesmo após este procedimento observou-se que no lado esquerdo ainda havia grande quantidade de efusão pleural, decidindose por fixar um dreno torácico de silicone apenas deste lado para posterior drenagem da efusão, já que o lado direito foi drenado satisfatoriamente (Figura 1B).

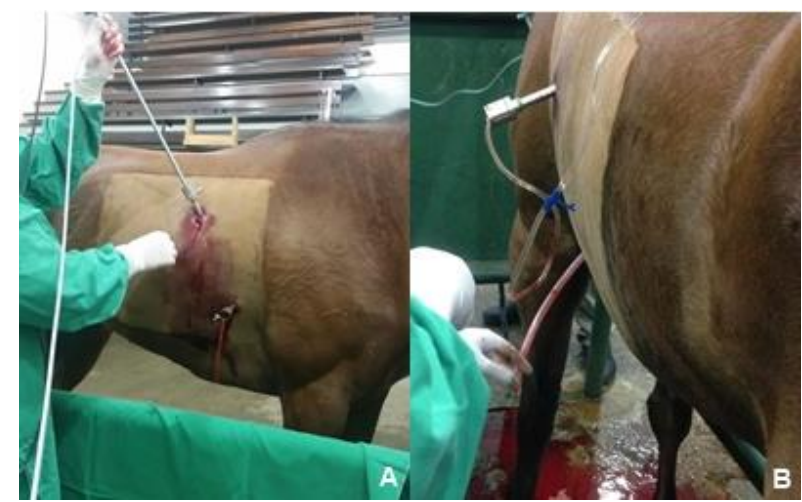

Figura 1 - Nota-se em A: - Acessos para inserção dos endotips para colocação do endoscópio e do dreno no $8^{\circ}$ e $6^{\circ}$ EIC respectivamente, do lado direito do tórax; Notase em B: - Acessos para inserção dos endotips para colocação do endoscópio e do dreno no $8^{\circ}$ e 6o EIC respectivamente, para lavagem da cavidade torácica com $\mathrm{NaCl} 0,9 \%$ e fixação do dreno de silicone, do lado esquerdo do tórax.

Após a retirada do endoscópio o pneumotórax foi desfeito com aspirador cirúrgico. Concomitantemente, foi realizada sutura em bloco (muscular, subcutâneo e pele) com fio monofilamentar, polipropileno ํㅡ 2, em pontos simples isolados. $\mathrm{Na}$ extremidade do dreno foi utilizada uma válvula unidirecional com o objetivo de permitir a drenagem do líquido, mas evitando a entrada de ar.

Diariamente, após a fixação do dreno, realizou-se exame ultrassonográfico para acompanhamento da eficácia da drenagem da efusão pleural, e também auscultas cardíaca e pulmonar e mensuração da temperatura corpórea. Os curativos foram realizados com clorexidina $2 \%$ e rifamicina até total cicatrização, e os pontos foram retirados após dez dias da toracoscopia.

Como protocolo terapêutico, instituiu-se administração de metronidazol na dose de $25 \mathrm{mg} / \mathrm{kg}$, BID, VO, por dez dias, associado à administração de ceftiofur na dose de $4,4 \mathrm{mg} / \mathrm{kg}$, SID, IM, por 11 dias. Após o término destas aplicações, iniciou-se administração de enrofloxacina $10 \%$ na dose de $7,5 \mathrm{mg} / \mathrm{kg}$, SID, VO, por 21 dias, devido ao seu amplo espectro de ação e facilidade de administração. A administração de dipirona $(25 \mathrm{mg} / \mathrm{kg}$, IM) foi realizada quando ocorriam picos febris. Para controle da dor e inflamação iniciou-se a terapia com Firocoxib na dose de $0,1 \mathrm{mg} / \mathrm{Kg}$, SID, VO, por 15 dias, e visando proteger a mucosa gástrica optou-se por iniciar o uso de um inibidor de bomba de prótons, diminuindo a secreção ácida (Omeprazol 8,5\%, 10g, SID, VO, por 16 dias).

Após 24 horas do primeiro exame ultrassonográfico, realizou-se um segundo exame, o qual evidenciou redução da quantidade de efusão pleural. Para controle da pleurodinia administrou-se $20 \mathrm{~mL}$ de bupivacaína pelo dreno, a cada seis horas, por cinco dias.

Cinco dias após a fixação do dreno no hemitórax esquerdo, este foi retirado e o ponto de incisão foi suturado com fio monofilamentar Náilon oㅜ 0 , em padrão simples isolado. No oitavo dia, na avaliação ultrassonográfica, observou-se acúmulo de líquido no hemitórax direito, optandose pela fixação de um dreno deste lado, o qual foi mantido por oito dias, até o desaparecimento total das áreas de efusão, observado no acompanhamento ultrassonográfico.

No $12^{\circ}$ dia realizou-se nova coleta de sangue para hemograma e bioquímica sérica e no $18^{\circ}$ dia após a 
data de entrada no HV o animal recebeu alta, sendo mantido apenas com administração oral de enrofloxacina $10 \%$, até completar 21 dias de tratamento.

\section{RESULTADOS E DISCUSSÃO}

As pleurisias, pneumonias e abscessos pulmonares são comuns nos cavalos de corrida. Isso decorre provavelmente das condições de estabulagem em baias fechadas e escuras, alta rotatividade de população e pelo exercício realizado para melhorar sua condição física (HENNINGER \& JONES, 1988). As pleuropneumonias têm sido associadas ao estresse, exercícios extenuantes e transportes longos, conduzindo a uma supressão das defesas pulmonares (CHAFFIN et al., 2000).

Está classificada como a doença que mais acomete cavalos submetidos ao transporte, relacionada à queda de imunidade devido ao estresse e aos agentes microbianos (PO et al., 2013). Os cavalos que são transportados cabresteados e amarrados, são impedidos do abaixamento da cabeça, favorecendo 0 acometimento da afecção, pois reduz a defesa natural das vias respiratórias, diminuindo a ventilação adequada, acarretando em problemas respiratórios (OIKAWA et al., 2005).

Os exames físicos do paciente após o procedimento apresentavam-se com parâmetros cardíacos e intestinais normais. O animal apresentava TPC e turgor de pele normais, caracterizando um grau de desidratação leve (de 5 a 7\%) (DEARO, 2001), porém estava ingerindo água, ração e feno normalmente. A frequência respiratória manteve-se estável entre 20 e $30 \mathrm{mpm}$, e a mucosa passou de levemente congesta para normocorada dois dias após a realização do procedimento. Foi observada leve pleurodinia logo após o procedimento, principalmente nas regiões próximas ao dreno.

Os resultados dos exames laboratoriais realizados no HV-UFPR evidenciaram, no primeiro hemograma, um quadro de leucocitose por neutrofilia, compatível com o processo bacteriano instalado, e fibrinogênio elevado, indicando fase aguda de inflamação (RAIDAL, 1995). Após o tratamento, no segundo hemograma, o paciente não apresentava leucocitose e neutrofilia, encontrando-se 0 fibrinogênio dentro dos valores de referência considerados normais para a espécie (KANEKO et al., 1997).

$\mathrm{Na}$ urinálise observou-se $\mathrm{pH}$ ácido $(6,0)$ e traços de proteína. A acidúria pode estar relacionada ao catabolismo de proteínas orgânicas que ocorre na febre e restrição alimentar; ou à acidose metabólica/respiratória, consequente à diminuição do $\mathrm{pH}$ sanguíneo e aumento da $\mathrm{PaCO} 2$ (LOPES \& BIONDO, 2009; VIU et al., 2010). A proteinúria pode estar associada à perda de albumina, já que as tiras de urinálise são sensíveis à estas, podendo ter origem pré-renal, renal ou pós-renal (LOPES \& BIONDO, 2009). Neste caso, a proteinúria parece ser causada por um aumento da permeabilidade vascular glomerular fisiológica, fato que ocorre em situações de estresse ou dor, uma vez que foram observados apenas traços e não foi acompanhada da presença de cilindros (GARCIA-NAVARRO, 1996).

No exame bacteriológico houve isolamento de Streptococcus equi $\beta$ hemolítico sensível ao metronidazol, ceftiofur e enrofloxacina, que foram, portanto, os antimicrobianos escolhidos para o tratamento do caso descrito: Ceftiofur, antibiótico bactericida que pertence ao grupo das cefalosporinas de terceira geração (SPINOSA, 1999), atua inibindo a síntese da parede bacteriana, possuindo maior espectro de ação contra bactérias gram-positivas, 
aprovada para 0 tratamento de pneumonias estreptocócicas em cavalos (DOWLING, 2004); Metronidazol, nitroimidazólico heterocíclico, de ação contra bactérias gram-negativas, causa quebra em cadeias de DNA e inibição da enzima de reparação do DNA (WILSON, 2001), indicado em pleuropneumonias para dar cobertura contra bactérias anaeróbicas (ARMENGOU, 2007); e Enrofloxacina, fluorquinolona que atua contra bactérias gram-positivas e negativas inibindo a DNA girase, levando a sua degradação (DOWLING, 2004).

$\mathrm{Na}$ realização dos acessos intercostais, a incisão de pele e divulsão da musculatura não acarretaram em hemorragia significativa. Durante a formação do pneumotórax o animal não apresentou dispneia, sendo apenas observado leve aumento na frequência e amplitude respiratórias. No hemitórax esquerdo foi drenado três litros de efusão, enquanto no direito um litro e meio. O líquido apresentava aspecto sanguinolento, turvo e inodoro, compatível com a descrição de Reed \& Bayly (2000), sendo que, segundo estes autores, as características do líquido pleural variam de acordo com a gravidade e cronicidade da doença, dependendo da quantidade de células inflamatórias, microorganismos, fibrina, e podendo ser sanguinolento ou purulento.

O exame ultrassonográfico foi fundamental para elucidar o diagnóstico, pois observou-se áreas de efusão pleural hipoecóica e anecóica com presença de estruturas lineares hiperecóicas (fibrina) no espaço pleural e áreas de hepatização pulmonar ventrais bilaterais, o que caracteriza aderências em casos de pleuropneumonia crônica. Esta consolidação pulmonar é identificada devido à perda de ecogenicidade e do padrão fisiológico de artefatos de reverberação, causados pela presença de ar nos pulmões (PUSTERLA et al., 2006).

Os casos de pleuropneumonia normalmente apresentam prognóstico favorável quando diagnosticados e tratados precocemente. $O$ uso de antimicrobianos adequados, analgésicos e anti-inflamatórios associados à drenagem da efusão pleural levam a uma melhora significativa do quadro, podendo o animal voltar a sua rotina. Diagnósticos ou tratamentos inadequados são associados ao prolongamento do curso da doença, levando a sequelas indesejáveis e pior prognóstico para o futuro esportivo do animal (RAIDAL, 1995).

Relata-se na literatura que os equinos são submetidos à toracoscopia desde 1980. Atualmente esta técnica tem sido utilizada tanto para diagnóstico como para tratamento de afecções torácicas (DE ZOPPA et al., 2001), sendo um procedimento que promove conforto e estabilização respiratória do cavalo devido à drenagem de grandes volumes de líquidos (RIBEIRO \& HENRIQUES, 2016). A presença de conteúdo na cavidade torácica promove compressão dos pulmões, bem como toxemia do paciente (caso o conteúdo seja de natureza séptica), e posteriormente bloqueio da expansão pulmonar (MARQUES, 1992c).

Seltzer \& Byars (1996), relataram que a colocação de drenos torácicos para drenagem massiva e precoce da efusão pleural resulta em alto índice de recuperação atlética dos animais, haja visto que os índices não diminuíram quando comparados à equinos que não necessitaram de drenagem. A drenagem faz-se necessária quando a efusão é séptica, devido a possibilidade de lavagem do espaço pleural com antibioticoterapia local (SCHOTT II \& MANSMANN, 1990). 
Segundo

Mansmann

\&

Bernardstrother (1985), as principais complicações da prática de toracoscopia são dor, infecção, pneumotórax e lacerações no tecido pulmonar, porém a administração de antibióticos e antiinflamatórios no pós-operatório diminui estas intercorrências.

Esta técnica teve um papel fundamental no tratamento da pleuropneumonia, e, como observado neste caso, não somente a lavagem foi suficiente, mas a colocação e manutenção de um dreno foram fundamentais, pois no hemitórax direito não foi fixado dreno inicialmente e apenas a lavagem não foi eficiente no tratamento, necessitando do dreno posteriormente. Desta forma, com a fixação de um dreno torácico sob visualização endoscópica, permitiu-se que a drenagem ocorresse de forma efetiva, aumentando a eficácia do procedimento, melhorando o quadro clínico e dando mais conforto respiratório ao animal.

\section{CONCLUSÃO}

Podemos verificar que a toracoscopia foi importante na condução do caso, bem como a manutenção do dreno torácico, pela sua facilidade, rapidez de execução, ampla visibilização da cavidade pleural e menor trauma ao paciente, promovendo - melhor prognóstico e conforto respiratório ao animal.

\section{REFERÊNCIAS}

ARMENGOU, L. Antibioterapia en medicina equina. Equinus: Medicina y cirugía equina. n.18, p. 20-30, 2007.

CHAFFIN, M. K.; CARTER, K.; DABAREINER, $R$. How to place indwelling chest tube for drainage and lavage of the pleural cavity in horses affected with pleuropneumonia. In:
Annual convention of the american association of equine practitioners, San Antonio, Texas. Proceedings of the American Association of Equine Practitioners, p.145-149, 2000.

DE ZOPPA, A. L. V.; ALVARENGA, J.; DA SILVA, L. C. L. C.; FERREIRA, M. A.; MIGLIATI, E. R. Toracoscopia em Equinos: Técnica e Emprego como Método de Avaliação da Cavidade Pleural. Ciência Rural. v. 31, n.5, p.825-830, 2001.

DEARO, A. C. O. Fluidoterapia em grandes animais - Parte I: água corpórea, indicações e tipos de fluidos. Revista de Educação Continuada em Medicina Veterinária - CRMV-SP. v. 4, n. 2. p. 3-8, 2001.

DOWLING, P. M. Antimicrobial therapy. In: BERTONE, J.J.; HORSPOOL, L. J. I. Equine Clinical Pharmacology. USA: Saunders, 2004. cap. 2, p. 12-47.

FREEMAN, D. E. Pleuroscopy. Veterinary Clinics of North America: Equine Practice, v.7, n.3, p.621-623, 1991.

GARCIA-NAVARRO, C. E. K. Manual de Urinálise Veterinária. 1ed. São Paulo: Varela. 1996. 96p.

HENNINGER, R.; JONES, D. Surgical treatment of chronic pleuritis in a horse. Equine Practice, v. 10 , n. 6, p. 13-16, 1988.

KANEKO, J. J.; HARVEY, J. W.; BRUSS, M. L. Clinical biochemistry of domestic animals. 5th ed. New York: Academic Press, 1997. 932p.

LIGHT, R. W.; GIRARD, W. M.; JENKINSON, S. G.; GEORGE, R. B. Parapneumonic effusions. America Medicine, v. 69, n.4, p. 507-512, 1980. 
LOPES, S. T. A.; BIONDO, A. W. Manual de Patologia Clínica Veterinária. $4^{\mathrm{a}}$ ed. Universidade Federal de Santa Maria, Centro de Ciências Rurais, Santa Maria RS, 2009. p. $72-73$.

MACKEY, V. S.; WHEAT, J. D. Endoscopic examination of the equine thorax. Equine Veterinary Journal, v.17, n.2, p.140-142, 1985.

MAIR, T. S. Pleural Effusions and Pleuropneumonia. In: British Equine Veterinary Association Congress Beva, 51. Birmingham, United Kingdom, 2012.

MANSMANN, R. A.; BERNARDSTROTHER, S. Pleuroscopy in horses. Modern Veterinary Practice, v.66, n.1, p.9-17, 1985.

MARQUES, E. Tórax agudo não traumático. In: O Tórax agudo estratégia e tática em cirurgia torácica de urgência. São Paulo: Sarvier, 1992c. p.155-175.

OIKAWA, M.; HOBO, S.; OYAMADA, T.; YOSHIKAWA, $\mathrm{H}$. Effects of orientation, intermittent rest and vehicle cleaning during transport on development of transport-related respiratory disease in horses. Journal of Comparative Pathology. v. 132, p.153-168, 2005.

PERONI, J. F.; HORNER, N. T.; ROBINSON, N. E.; STICK, J. A. Equine thoracoscopy: normal anatomy and surgical technique. Equine Veterinary Journal. v. 33, n. 3, p.231-237, 2001.

PO, E., WILLIAMS, C., MUSCATELLO, G., CELI, P. Assessment of oxidative stress biomarkers in exhaled breath condensate and blood of Thoroughbred foals. Veterinary Journal. v. 196, p. 269-271, 2013.
PUSTERLA, N.; WATSON, J. L.; WILSON, D. Diagnostic approach to infectious respiratory disorders. Clinical Techniques in Equine Practice. v. 5, p.174-186, 2006.

RAIDAL, S. L. Equine Pleuropneumonia. British Veterinary Journal. v. 151, n. 3, p.233-262, 1995.

REED, S. M.; BAYLY, W. M. Sistema Respiratório. In: Medicina Interna Equina.

Rio de Janeiro: Guanabara Koogan, 2000. cap.6, p. 217-249.

RIBEIRO, T. A.; HENRIQUES, M. O. Pleuropneumonia em equino do Exército Brasileiro: relato de caso. Revista Eletrônica do CESVA - Saber Digital. v. 9, n. 1, p. 136-144, 2016.

SCHOTT II, H. C.; MANSMANN, R. A. Thoracic drainage in horses. Compendium on Continuing Education for the Practicing Veterinarian, v. 12, n. 2, p. 251-261, 1990.

SELTZER, K. L.; BYARS, T. D. Prognosis for retum to racing after recovery from infectious pleuropneumonia in Thoroughbred racehorces: 70 cases (1984-1989). Journal of the American Veterinary Medical Association, v. 208, n. 8, p.1300-1301, 1996.

SPINOSA, H. S. Antibióticos betalactâmicos: Penicilinas e Cefalosporinas. In: SPINOSA, H. S.; GÓRNIAK, S. L.; BERNARDI, M. M. Farmacologia Aplicada À Medicina Veterinária. 2. Ed. Rio de Janeiro: Guanabara Koogan, 1999. cap. 37, p. 389-395.

SWEENEY, C. R.; REILLY, L. K. Sistema Respiratório. In: SAVAGE, C. J. 
Segredos em Medicina de Equinos.

Porto Alegre: Artmed, 2001, cap. 9, p. 416.

VACHON, A. M.; FISCHER, A. Thoracoscopy in the horse: diagnostic and therapeutic indications in 28 cases. Equine Veterinary Journal, v.30, n.6, p.467-475, 1998.

VIU, J.; JOSE-CUNILLERAS, E.; ARMENGOU, L.; CESARINI, C.; TARANCÓN, I.; RIOS, J.; MONREAL, L. Acid-base imbalances during a $120 \mathrm{~km}$ endurance race compared by traditional and simplified strong ion difference methods. Equine Veterinary Journal, v. 38, p. 76-82, 2010.

WILKINS, P. A. Lower airway diseases of the adult horse. Veterinary Clinics of North America: equine practice. v. 19, n. 1, p. 101-121, 2003.

WILSON, W. D. Rational Selection of Antimicrobials for use in Horses. American Association of Equine Practitioners, v. 47, p. 75-93, 2001. 